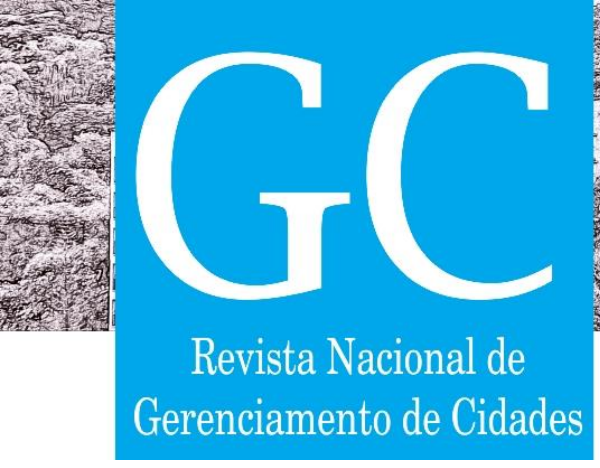

\title{
Habitação e Cidade. O Caso dos Conjuntos Habitacionais Jaguariúna I e II Diante do Processo de Dispersão Urbana e da Produção do Programa Minha Casa Minha Vida no "Eixo Campinas-Mogi"
}

Housing and City. The Case of Jaguariúna I and II Housing Complexes Facing the Urban Sprawl Process and the Production of the Minha Casa Minha Vida Program in the "CampinasMogi Axis"

Vivienda y Ciudad. El Caso de los Complejos de Viviendas Jaguariúna I y II Frente al Proceso de Dispersión Urbana y la Producción del Programa Minha Casa Minha Vida en el "Eje Campinas-Mogi"

Caio Barbato Maroso Pontifícia Universidade Católica de Campinas. POSURB caio.arqui@gmail.com

Luiz Augusto Maia Costa Pontifícia Universidade Católica de Campinas luiz.augusto@puc-campinas.edu.br 
Revista Nacional de Gerenciamento de Cidades

Resumo: este artigo apresenta o estudo de caso dos Conjuntos Habitacionais Jaguariúna I e II, localizados na cidade de Jaguariúna, Brasil. Esses conjuntos foram executados com recursos federais viabilizados no âmbito do Programa Minha Casa Minha Vida, que é desde 2009 a principal iniciativa pública de provisão habitacional. 0 objetivo do estudo foi mostrar que os diversos problemas de gestão, em diferentes escalas, possibilitam que os conjuntos produzidos por esse programa acentuem o processo de urbanização dispersa, em processo na região em que se encontram esses casos. Na perspectiva regional, o cenário é de continuidade enquanto na escala intraurbana é de ruptura. O método proposto se baseia no estudo de diferentes escalas de análise e na história social, que dá suporte para as tomadas de dados em fontes não oficiais. Os principais resultados revelaram que Jaguariúna I e II não garantem o direito à moradia adequada e à cidade; acentuam o processo de urbanização dispersa; obedecem ao interesse privado pela reprodução do capital; e que o padrão condominial agrava os problemas de gestão.

Palavras-chave: Gestão Urbana; Gestão Pública; Habitação Social; Urbanização Dispersa; Programa Minha Casa Minha Vida.

Abstract: this paper presents the case study of Jaguariúna I and II Housing Complexes, located in the city of Jaguariúna, Brazil. These sets were executed with federal funds made available under the Minha Casa Minha Vida Program, which has been the main public housing provision initiative since 2009. The aim of the study was to show that the various management problems, at different scales, allow the sets produced by this program to accentuate the process of urban sprawl, which is in process in the region where these cases are found. In the regional perspective, the scenario is one of continuity while on the intra-urban scale it is one of rupture. The proposed method is based on the study of different scales of analysis and social history, which supports data collection from unofficial sources. The main results revealed that Jaguariuna I and II do not guarantee the right to adequate housing and the city; accentuate the process of dispersed urbanization; they obey the private interest in the reproduction of capital; and that the condominium standard aggravates management problems.

Key words: Urban Management; Public Management; Social Housing; Urban Sprawl; Minha Casa Minha Vida Program.

Resumen: este artículo presenta el estudio de caso de los complejos de viviendas Jaguariúna I y II, ubicados en la ciudad de Jaguariúna, Brasil. Estos conjuntos se llevaron a cabo con fondos federales disponibles bajo el Programa Minha Casa Minha Vida, que ha sido la principal iniciativa de provisión de vivienda pública desde 2009. El objetivo del estudio fue mostrar que los diversos problemas de gestión, a diferentes escalas, permiten que los conjuntos producidos por este programa acentúen el proceso de urbanización dispersa, que está en proceso en la región donde se encuentran estos casos. En la perspectiva regional, el escenario es de continuidad mientras que en la escala intraurbana es de ruptura. El método propuesto se basa en el estudio de diferentes escalas de análisis e historia social, que respalda la recopilación de datos de fuentes no oficiales. Los principales resultados revelaron que Jaguariúna I y II no garantizan el derecho a una vivienda adecuada y a la ciudad; acentúan el proceso de urbanización dispersa; obedecen al interés privado en la reproducción del capital; y que el estándar de condominio agrava los problemas de gestión.

Palabras clave: Gestión Urbana; Gestión Pública; Vivienda Social; Dispersión Urbana; Programa Minha Casa Minha Vida. 



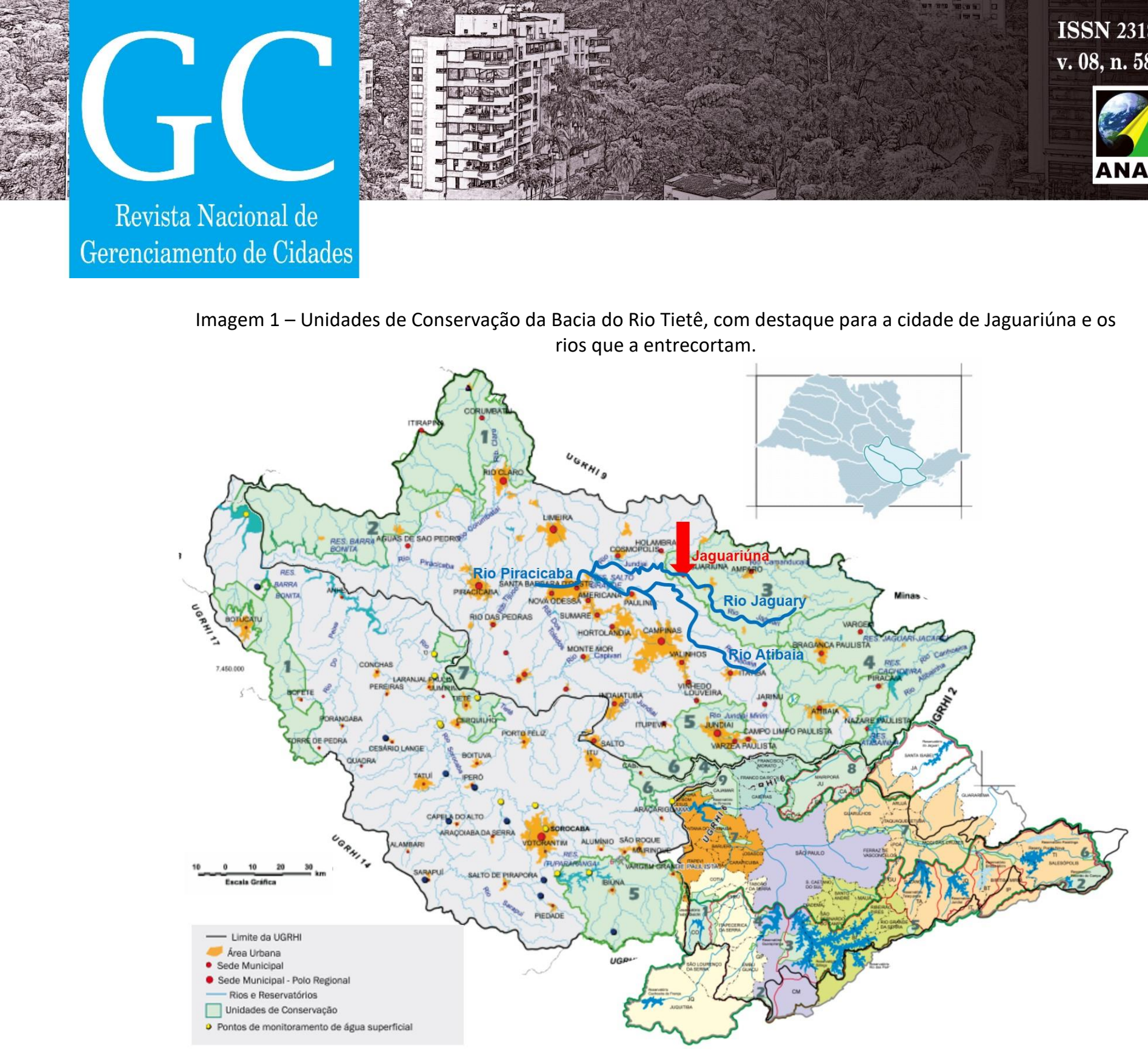

Fonte: adaptado de SigRH, Sistema Integrado de Gerenciamento dos Recursos Hídricos do Estado de São Paulo. É possível notar a inserção de Jaguariúna, e dos rios que a entrecortam, com outros municípios e rios que integram a bacia hidrográfica do Rio Tietê.

Atualmente, Jaguariúna conta com um parque industrial significativo, com empresas de grande porte, como Motorola, Ambev e Sky ${ }^{1}$, além de apresentar diversos condomínios industriais, ocupados por organizações de menor porte. A presença de condomínios residenciais fechados, destinados à população de alto poder aquisitivo, como o Haras Patente e o Tamboré Jaguariúna, têm se intensificado. Na maioria dos casos, eles ficam apartados do núcleo urbano principal e ligados à Rodovia Gov. Dr. Adhemar Pereira de Barros (SP-340), principal via de acesso à cidade e que liga Jaguariúna a Campinas e ao sul do estado de Minas Gerais. O município ainda é sede da RED Eventos, casa de shows integrada às agendas culturais nacional e internacional, e do Centro Universitário de Jaguariúna, instituição privada de ensino e pesquisa, que atendem à cidade e à região. Segundo o IBGE, em 2010, o IDHM era 0,784 (índice alto, se comparado com a média nacional, que para o mesmo ano foi 0,699 ), e o PIB, 16,7 bilhões de reais. Ainda segundo o mesmo Instituto, a população estimada para 2016 foi de 53 mil habitantes.

\footnotetext{
1 Motorola, Ambev e Sky são três indústrias multinacionais. A primeira, atua no ramo da tecnologia, sobretudo no desenvolvimento e na produção de smartphones. A segunda, do ramo alimentício, é reconhecida pela produção de cerveja, entre outros. A terceira é distribuidora de sinal de canais de televisão, no ramo das telecomunicações.
} 


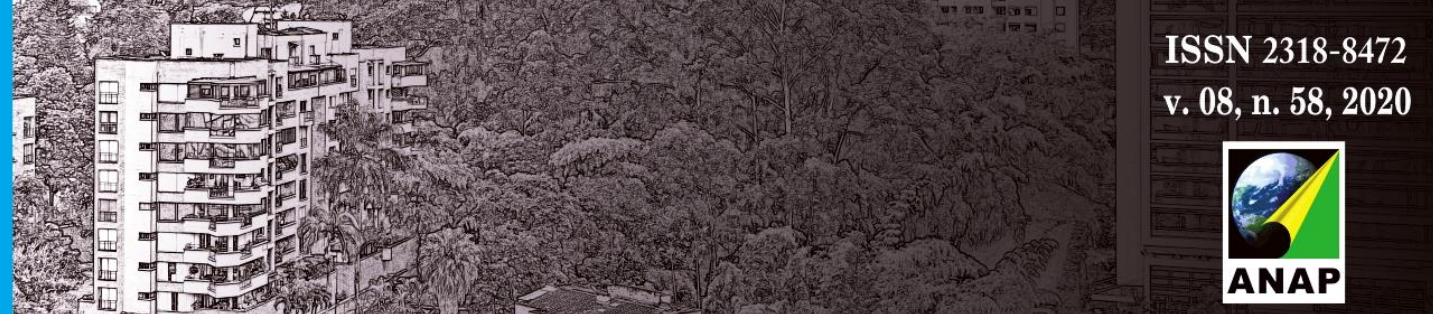

\section{Revista Nacional de}

Gerenciamento de Cidades

Jaguariúna está inserida no que se denominou por "Eixo Campinas-Mogi", que definiu o recorte territorial da dissertação de mestrado que originou este artigo. O Eixo foi definido com base nas relações socioespaciais observadas no local e possui a Rod. Gov. Dr. Adhemar Pereira de Barros (SP340) como via principal e estruturadora, sendo que ela possui função estrutural nas dinâmicas do cotidiano dos usuários do Eixo e da população das seis cidades que participam desse recorte. Além de Jaguariúna, Campinas, Holambra, Santo Antônio de Posse, Mogi Mirim e Mogi Guaçu conformam o território analisado. A posição central de Jaguariúna faz com que ela guarde estreita relação com as demais cidades, tendo em vista a facilidade do acesso por meio da via principal. Das cidades mencionadas, apenas Mogi Mirim e Mogi Guaçu não fazem parte da Região Metropolitana de Campinas, porém, de acordo com o estudo realizado, elas participam igualmente das dinâmicas metropolitanas, tanto nas dinâmicas populacionais quanto economicas.

A Região Metropolitana de Campinas (RMC) ganhou destaque nacional nos últimos anos, por concentrar polos industriais de alta tecnologia e centros importantes de ensino e pesquisa. Ela abriga sede de empresas multinacionais (Motorola, IBM, Dell, Sky, Santander Data Center) e de universidades (Unicamp, PUC-Campinas) conhecidas internacionalmente pela produção de conhecimento e tecnologia. A junção de produção de conhecimento e tecnologia resultou em algumas comparações entre a região de Campinas e a do Vale do Silício norte-americano. A RMC começou a se formar no início da década de 1970, com o processo de descentralização industrial, partindo da cidade de São Paulo em direção ao interior do estado e a outros estados brasileiros. A RMC, então, passou por um processo de urbanização dispersa, que pode ser percebido tanto em seu território quanto nas dinâmicas socioespaciais.

\section{LOCALIZAÇÃO DOS CONJUNTOS HABITACIONAIS JAGUARIÚNA I E II}

A dispersão urbana e a suburbanização não são fenômenos recentes, tampouco exclusivamente brasileiros. Eles são remetidos ao desenvolvimento da revolução industrial e a impossibilidade de aumento das densidades nos centros das cidades, sendo a ocupação da periferia uma alternativa ao crescimento da população urbana. É necessário pontuar que essa alternativa foi viabilizada pelas inovações nos meios de transporte, como o carro e as rodovias, e que ela transformou as cidades, trazendo uma nova relação dicotômica entre centro-periferia. Essa nova maneira de ocupar as cidades pode ser observada em diversos países do ocidente, porém com características diferentes. Entendese que o caso brasileiro se aproxime mais das características observadas nos países europeus do que nos norte-americanos, visto que as zonas periféricas são ocupadas, mais comumente, pela população de baixa renda, como será explicado adiante. Porém, há de se considerar que existe também uma aproximação dos subúrbios norte-americanos de casas isoladas no lote, adaptados à realidade brasileira pelos condomínios fechados, em que os conjuntos de casas são cercados por muros e o acesso é controlado por portaria. (TAYLOR, 2015; CALDEIRA, 1997; HOBSBAWM, 1990; CHOAY, 1965) Choay (1965) identifica, no processo de suburbanização, espaços vagos entre as ocupações urbanas das cidades. Esses espaços são denominados como vazios urbanos e se apresentam como área potencial para intervenções na cidade, podendo abrigar equipamentos urbanos ou, mesmo, novas habitações em lugares consolidados. Porém, o que se observa é a especulação imobiliária da terra, aguardando a máxima valorização dessas áreas, para então serem destinadas a usos nem sempre socialmente interessantes, servindo apenas à reprodução do capital. (HARVEY, 2001)

De forma geral, no Brasil, o posicionamento da Habitação Social no território se repete historicamente, sendo localizada às margens das malhas urbanas consolidadas, de forma periférica, em regiões com pouca infraestrutura urbana, quando não ausente, onde o preço da terra é mais baixo. $O$ custo a ser pago pelo terreno em que serão construídas as casas para a população mais pobre representa um 




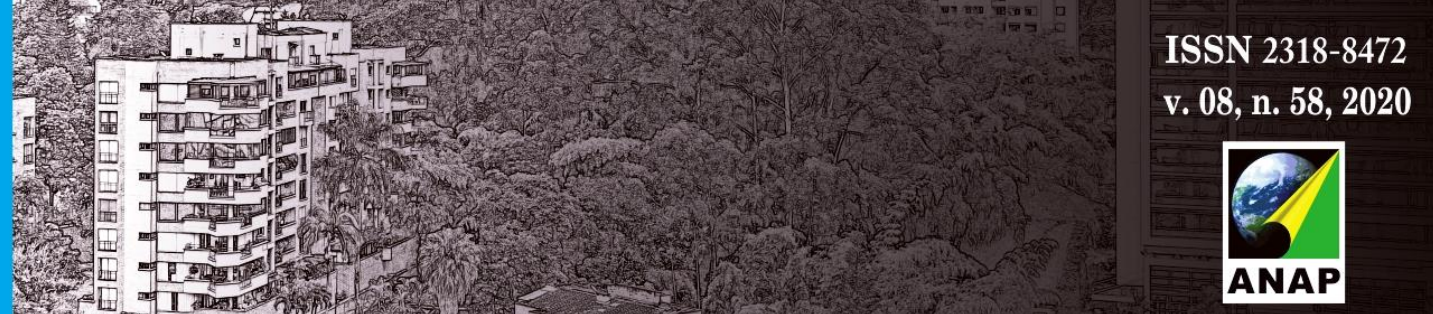

\section{Revista Nacional de}

Gerenciamento de Cidades

Na Imagem 3 é possível perceber que o território da megalópole é compreendido entre as cidades do Rio de Janeiro e de Campinas, perpassando dois estados e diversos municípios. Por estar na região sudeste, a mais rica do país, ela concentra população, mão de obra qualificada e oferta de empregos e serviços. Além disso, notam-se os vetores de crescimento em direção à região sul, ao interior dos estados de São Paulo e Rio de Janeiro e ao estado de Minas Gerais. O traço vermelho, inserido sobre a imagem original, mostra o Eixo Campinas-Mogi. Um trecho dele está inserido na megalópole e outra parte está em um dos vetores de expansão, que aponta para a cidade de Poços de Caldas, no interior do estado de Minas Gerais, o que ajuda a demonstrar a importância do território em estudo, bem como as dinâmicas encontradas. Essa região está sendo visada por grandes investimentos industriais, sobretudo ligados ao desenvolvimento de alta tecnologia, como o Centro de Pesquisa e Desenvolvimento (CPqD) e os Data Centers dos grupos Itau-Unibanco e Santander ${ }^{4}$, que se instalaram ali há menos de três anos. A presença de grandes universidades e centros de pesquisa (como a Unicamp e a Pontifícia Universidade Católica de Campinas - PUC-Campinas) reforçam a ideia do desenvolvimento tecnológico vinculado à pesquisa e ao ensino.

É importante ressaltar, frente ao cenário de formação da Megalópole do Sudeste Brasileiro, as novas relações socioespaciais que já se apresentam, e que devem se intensificar no futuro próximo, em consonância com teorias existentes acerca de fenômenos como esse. A junção territorial de grandes metrópoles em um único território deve levar ao extremo conceitos como globalização; fluxos de capital; surgimento e aplicação de novas tecnologias, com ênfase nos transportes; a compreensão da lógica espaço-tempo; a organização da hierarquia urbana; o estabelecimento das redes de lugares e lugares em rede; e a variedade dos deslocamentos populacionais. Dessa forma, espera-se, mais uma vez a ressignificação e alternância dos locais e modos de produção e transporte. (HARVEY, 2001; CASTELLS, 1998; SASSEN, 1988)

Harvey $(2010,2001)$ analisa a produção e a transformação do espaço construído a serviço da reprodução do capital. Alguns investimentos se destacam nessa investida, como a produção e a transformação dos territórios. Além desses, a produção de pesquisa científica, o turismo e a indústria de tecnologia de ponta são outros campos de investimento na busca pela reprodução do capital. 0 sistema capitalista exige a abertura de novas frentes para investimento, sendo a conquista de novos mercados e a quebra de barreiras que impossibilitem a livre circulação do capital, necessárias para a sobrevivência desse sistema. Assim também acontece com negociações do espaço urbano. A descentralização industrial, pela qual passou a RMSP, fez com que o território dessa metrópole fosse reconstruído, substituindo e adequando a infraestrutura para as necessidades da nova produção, pautada pelo setor terciário. Concomitantemente, a infraestrutura das demais regiões teve de ser construída e adaptada para receber as indústrias que deixaram a RMSP.

Quando uma área já urbanizada está desvalorizada, aplica-se capital em novas infraestruturas nesta área, aumentando os preços e o interesse por ela, gerando lucros que superam os investimentos feitos. Nessa lógica, também está inserido o espaço da cidade destinado à habitação, excluindo a parcela da população de menor renda, que não é atendida pelo mercado formal. Essa outra forma de investida no espaço urbano, de acordo com o autor, pode ser percebida nas alterações e no reestabelecimento do lugar em que está a produção e os mercados, como resultado da relativização do posicionamento, causada sobretudo pela modificação nos recursos e transportes. (HARVEY, 2001).

\footnotetext{
${ }^{4}$ Data Centers são galpões em que se localizam os servidores das instituições bancárias. Esses servidores armazenam todos os dados informacionais das transações realizadas, bem como as processam. Itaú-Unibanco é, atualmente, a maior instituição bancária brasileira, declarou, em 2018, lucro de 6,5 bilhões de dólares (considerando a cotação de dezembro de 2018). Santander é uma instituição bancária global, originária da Espanha e, atualmente, a maior da zona do Euro, declarou, em 2018 no Brasil, lucro de 3,1 bilhões de dólares (considerando a cotação de dezembro de 2018).
} 


\section{Revista Nacional de}

Castells (1998) indica que a nova forma de organização do modo de produção, a partir dos centros de comando distanciados do local de produção, altera o arranjo das cidades globais e, consequentemente, o território delas. A própria localização da indústria nesse território foi alterada de acordo com as possibilidades das conexões tecnológicas que garantem a gerência à distância. A alteração na forma urbana é um processo em que os espaços de fluxo são estruturalmente predominantes. Observa-se, então, a aproximação desse novo arranjo das metrópoles com a dispersão urbana, uma vez que a proximidade entre os centros de comando e o espaço de produção já não são mais necessários. Dessa forma, a dispersão e o espraiamento não simbolizam obstáculos para a gerência dos fluxos produtivos, desde que esses espaços sejam dotados da infraestrutura lógica necessária para tal. Por isso, como explica Castells (1998), a alteração das cidades já não responde mais à forma, mas aos processos.

O cenário que se observa na escala regional se repete no município de Jaguariúna, estudado nesta pesquisa. Na Imagem 4 é possível perceber que o crescimento da malha urbana desse município se comportou de forma diferente, de acordo com o avançar das décadas e do desenvolvimento regional. Até a década de 1970, a urbanização aconteceu na extensão do núcleo urbano original, sendo que posteriormente ela se deu de forma descontínua e fragmentada. A partir dos anos 2000 se verifica o surgimento dos condomínios residenciais horizontais, localizados nas áreas de expansão urbana ao longo da via principal que estrutura o Eixo. Além disso, notou-se o aumentado na ocorrência dessa modalidade nos últimos anos.

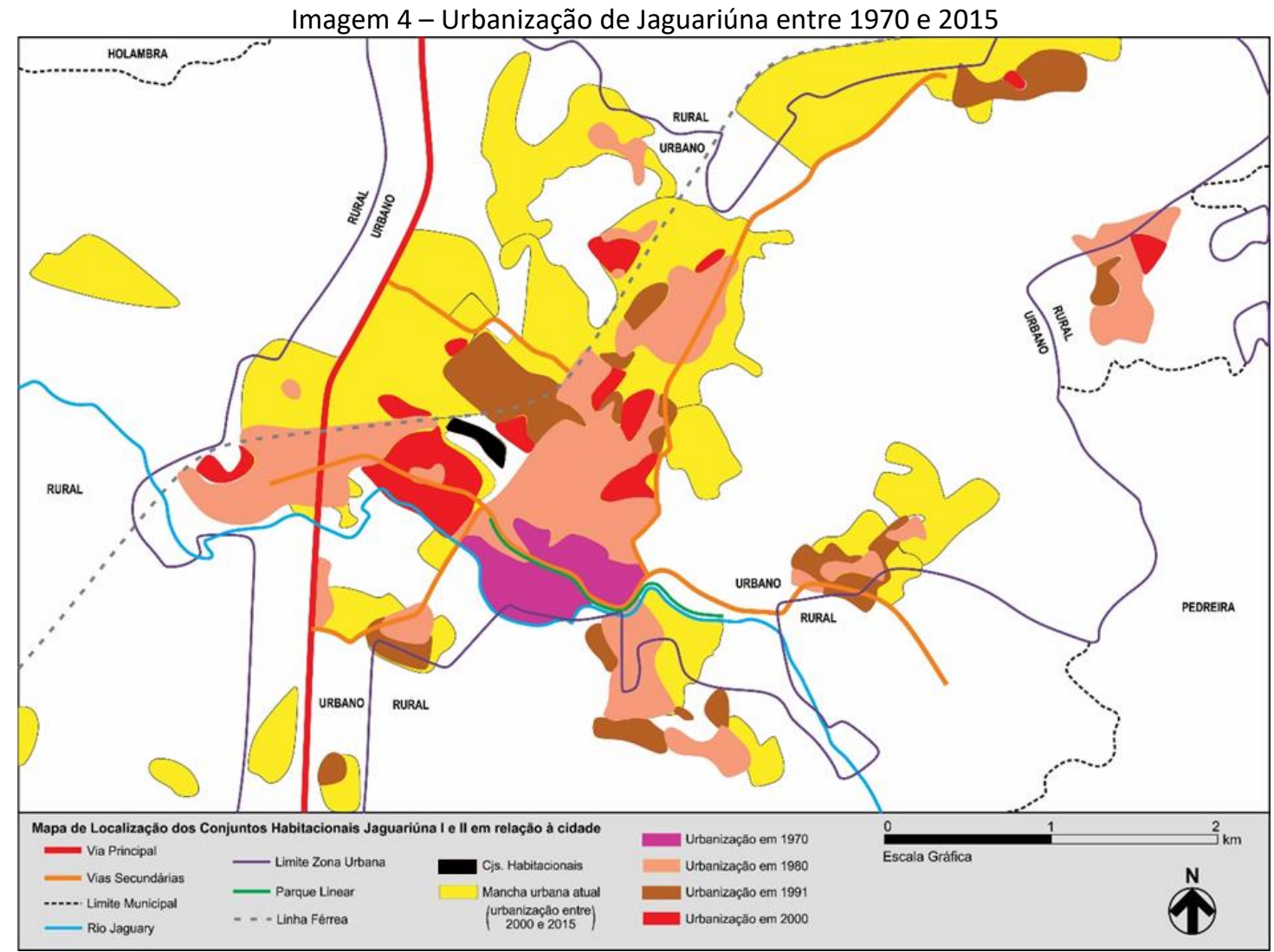

Fonte: elaborado de acordo com Monteiro (2007). O território ocupado após a década de 1970, início da observação da dispersão urbana, ocorre descolado da mancha urbana principal. 


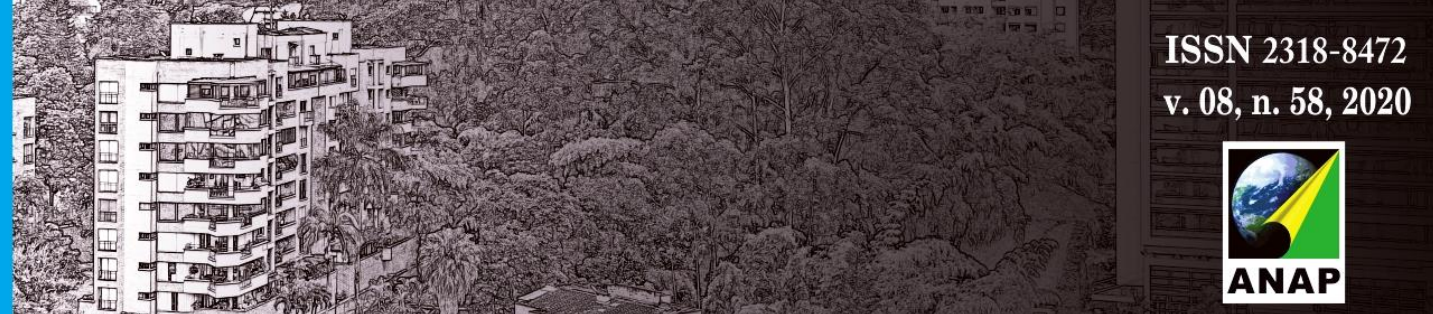

\section{Revista Nacional de}

Gerenciamento de Cidades

Dessa forma, uma análise prévia da localização dos Conjuntos Habitacionais Jaguariúna I e II ressalta, além da divergência com o padrão encontrado no PMCMV, também destoar do processo de urbanização do município em que está inserido. De fato, pelo que se observou historicamente, os dois conjuntos em tela não foram produzidos em local que reproduzisse o que é mais comum em Jaguariúna, porém esse fato também não foi suficiente para garantir a "boa localização" das moradias produzidas, como será abordado na análise da escala intra-urbana. O que se observa no território de Jaguariúna não é diferente nos demais municípios do Eixo Campinas-Mogi e da RMC, que passaram pelo processo de urbanização disperso, vinculado aos fenômenos expostos anteriormente e às condições explicadas por Harvey $(2010,2001)$ e por Castells (1998).

A Imagem 4 ainda apresenta o posicionamento dos Conjuntos Habitacionais Jaguariúna I e II (identificados pela forma em preto) em relação ao município. Evidencia-se a posição central deles em relação à mancha urbana consolidada, a proximidade com o núcleo urbano original (identificado pelas formas em roxo) e a contraposição em relação à urbanização entre os anos 2000 e 2015 (identificada pelas formas em amarelo). Essa evidência reforça o que foi afirmado anteriormente sobre a noção de "boa localização" que essas condições parecem conceder às moradias produzidas em Jaguariúna. Porém, é necessário ressaltar outras informações no mapa, como a ausência de mancha urbana no entorno imediato dos conjuntos (representado pela cor branca) e a proximidade de barreiras físicas. No caso, a linha férrea (representada pela linha cinza tracejada) e as vias secundárias (representadas pelas linhas em cor de laranja). Os vazios urbanos e as barreiras físicas dificultam o acesso aos conjuntos e produzem cidades fragmentadas, como será visto na sequência, ao ser analisada a escala intra-urbana.

\section{ANÁLISE INTRA-URBANA}

A proposta da análise intra-urbana é perceber, no estudo de caso particular, como as condições observadas na escala regional se refletem na cidade. Ainda que o estudo tenha sido feito para Jaguariúna, foram encontrados indícios de que as demais cidades do Eixo Campinas-Mogi tenham características próximas às encontradas nesta pesquisa. 0 método de análise proposto foi baseado nas referências de pesquisas de teor parecido, publicadas pelo LabCidade ${ }^{5}$, que consideraram a disponibilidade de serviços urbanos nas proximidades dos conjuntos analisados. Para tanto, os serviços foram divididos em três níveis de uso (cotidiano, eventual e esporádico), tendo medidas de tempo e distância para verificar o atendimento ou a ausência de determinado serviço.

A Imagem 5 mostra o resultado dessa verificação, para os Conjuntos Habitacionais Jaguariúna I e II, nos serviços de uso cotidiano. Nela encontram-se os equipamentos públicos disponíveis num raio de $1 \mathrm{~km}$ a partir dos conjuntos. É possível observar que tais equipamentos, ainda que se encontrem dentro da distância mínima, se concentram na margem do limite e atendem somente parte das necessidades da população. Além disso, há três barreiras físicas que dificultam a integração dos conjuntos com a cidade: a via secundária (Rod. João Beira); a via arterial (Av. Luciano V. Poltronieri); e a linha férrea. Nessa perspectiva, apenas uma escola municipal está dentro da distância considerada adequada e sem estar separada pelas barreiras. Os conjuntos em questão foram implantados entre dois bairros já consolidados, Cruzeiro do Sul e Jardim Dona Irma (identificados na Imagem 6). Porém, a linha férrea, os vazios urbanos e as vias de difícil travessia que conformam a área dos conjuntos não permitiram a integração deles a nenhum desses bairros e nem ao restante da cidade.

\footnotetext{
${ }^{5}$ Cf. publicações do LabCidade durante o ano de 2015, disponíveis em: <http://www.labcidade.fau.usp.br/biblioteca/>. Acesso em 08 mar. 2017.
} 


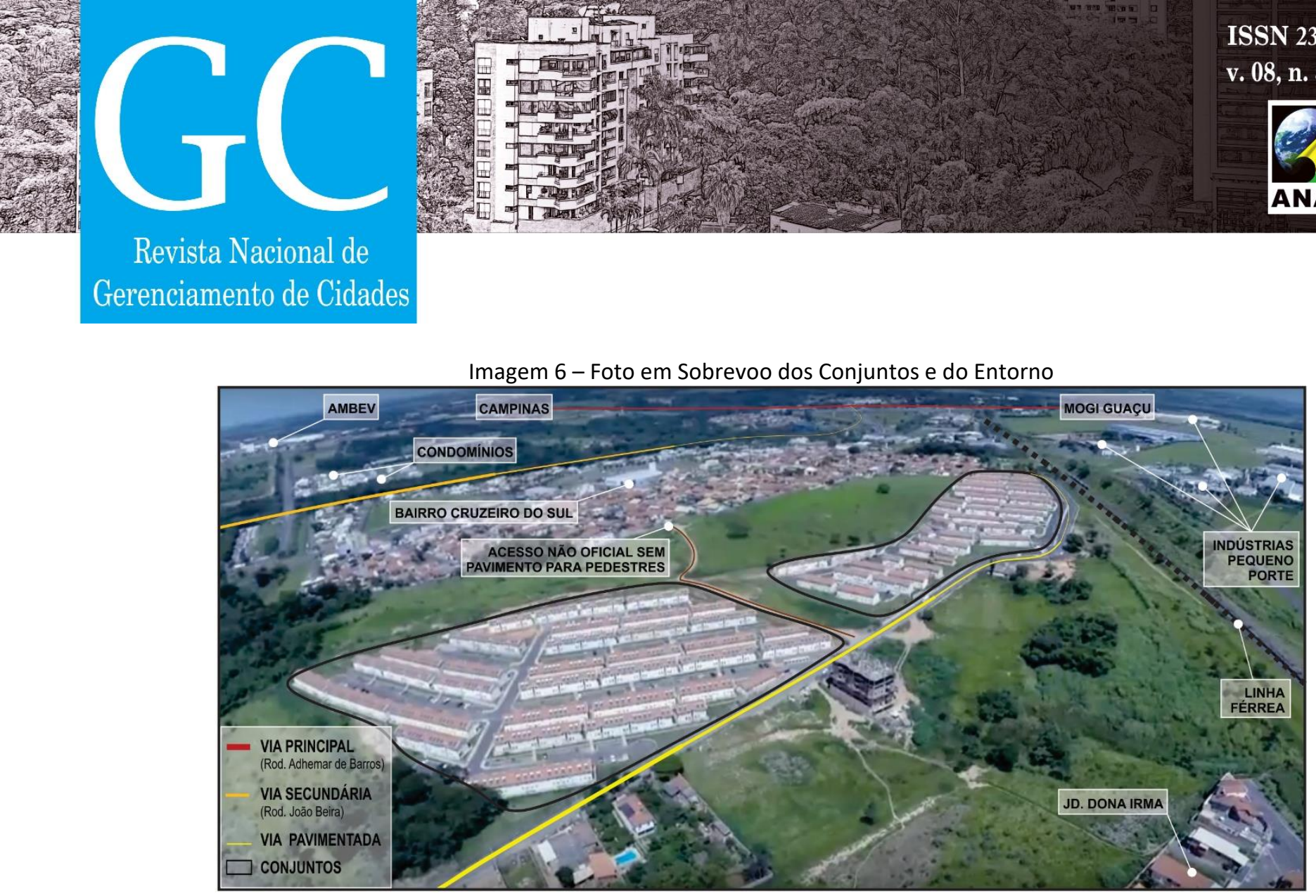

Fonte: adaptada de Rodhiumix, de acordo com a pesquisa de campo. Esq. Jaguariúna I; dir. Jaguariúna II.

Nota-se, ainda na Imagem 6, que existe um edifício em construção ao lado dos conjuntos, indicando uma possível ocupação futura das áreas vazias e que aumente a oferta dos serviços urbanos nas proximidades. Nesse sentido, também foram encontrados indícios de que esses vazios façam parte de um movimento de especulação urbana, que se utilizará das melhorias urbanas feitas para a implantação dos conjuntos, para alcançarem preços superiores. Esse indício provém do fato de que um dos confrontantes de um dos terrenos que abrigaram os conjuntos participar de uma trama de sociedades empresariais, cuja soma do capital social ultrapassa os 51 milhões de reais (aproximadamente 16,4 milhões de dólares, convertidos no início de 2017), e que atuam, também, no mercado imobiliário e de incorporações.

O que se observa nesse fato é a aplicação real do conceito "nó da terra". O patrimonialismo, característico da política urbana brasileira determina os investimentos e o desenho urbano das cidades, tirando proveito das benfeitorias públicas em infraestrutura. Supõe-se, nesse caso, que os proprietários das áreas vazias do entorno dos dois empreendimentos analisados estejam aguardando a máxima valorização do preço da terra, para então dar uso a elas. Maricato (1999). Esse fato também vai ao encontro do que propõe Harvey (2001), ao demonstrar de que maneira a reprodução do capital molda o espaço urbano. A detenção dessas glebas e a ociosidade desses espaços estão a serviço do capital privado e de sua reprodução. Enquanto isso, elas ficam indisponíveis para a cidade, esperando a vontade de seus proprietários em utilizá-las. Um dos problemas gerados pela especulação é que, enquanto se espera a máxima valorização da terra, os moradores dessas áreas sentem os impactos da segregação socioespacial.

Por sua vez, as questões apresentadas se refletiram na implantação desses dois empreendimentos. A falsa sensação de segurança passada pelos alambrados não é suficiente para barrar a exclusão causada pelos vazios. Contudo, é necessário ressaltar, de acordo com as entrevistas feitas com os síndicos dos condomínios, que a população de baixa renda entende que o padrão condominial traz segurança e é visto como qualidade do espaço construído. Essa afirmação é possível a partir dos pedidos dos condôminos de haver a troca do alambrado por muro, imaginando que este traria maior segurança. Porém, é justamente essa fragmentação da cidade que leva à insegurança, o que deveria indicar a dissolução do fechamento, e não o reforço dele. Aqui, percebe-se uma incoerência entre a fala e a 


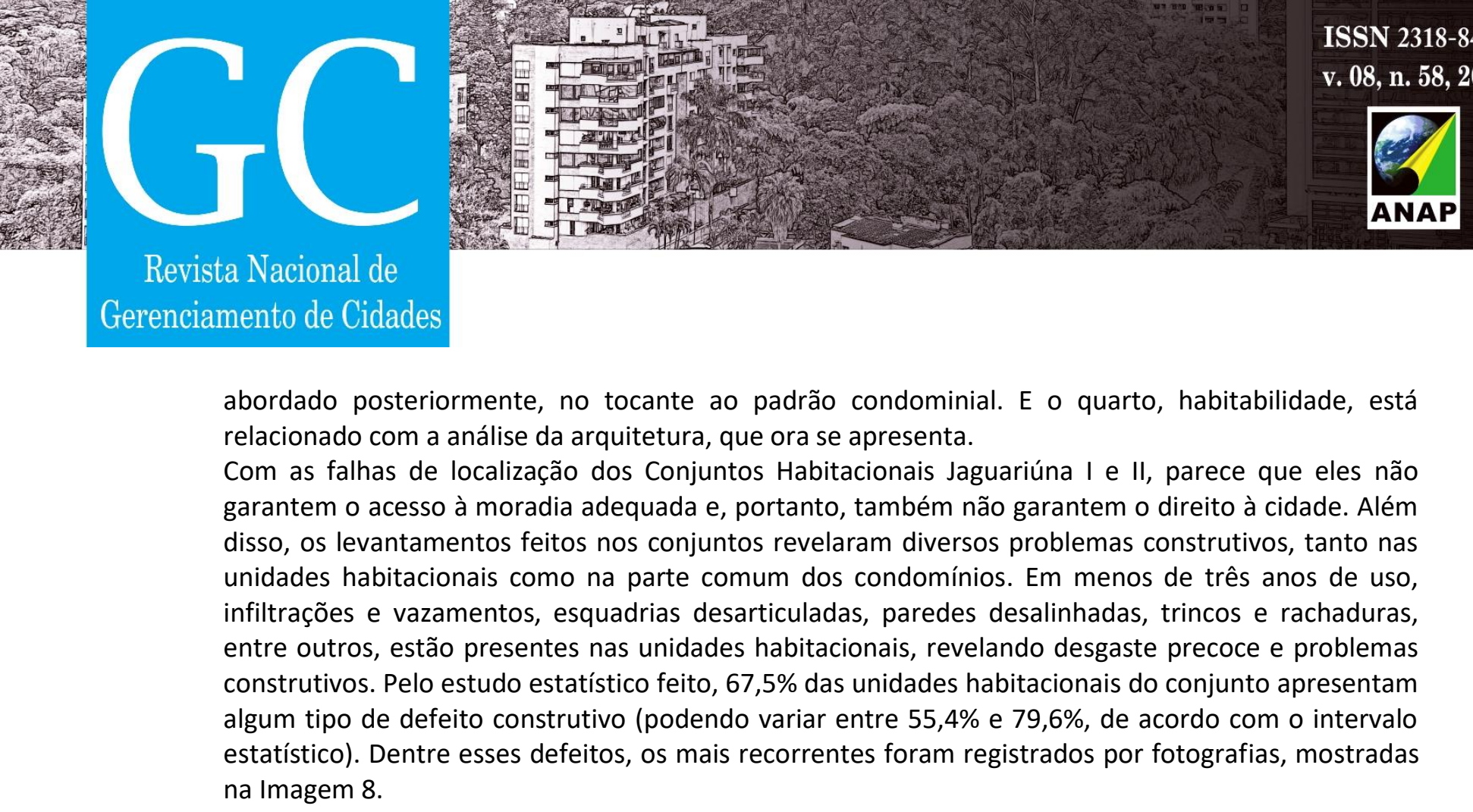

Imagem 8 - Problemas construtivos encontrados nas unidades habitacionais

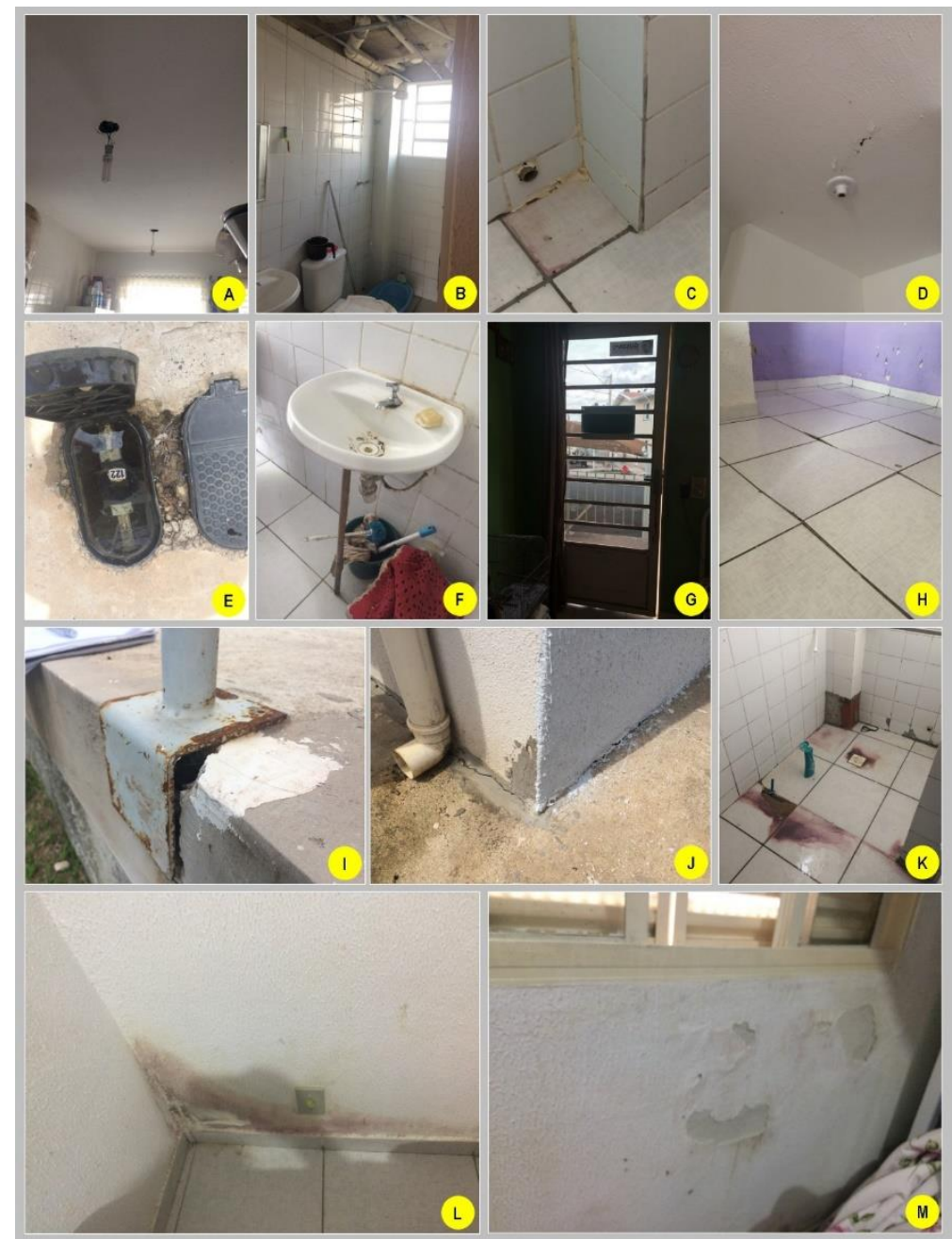

Fonte: capturadas no local, entre os dias 26 out. e 01 nov. de 2016. As fotografias ilustram e registram os problemas construtivos encontrados nas unidades habitacionais dos Conjuntos Habitacionais Jaguariúna I e II. 


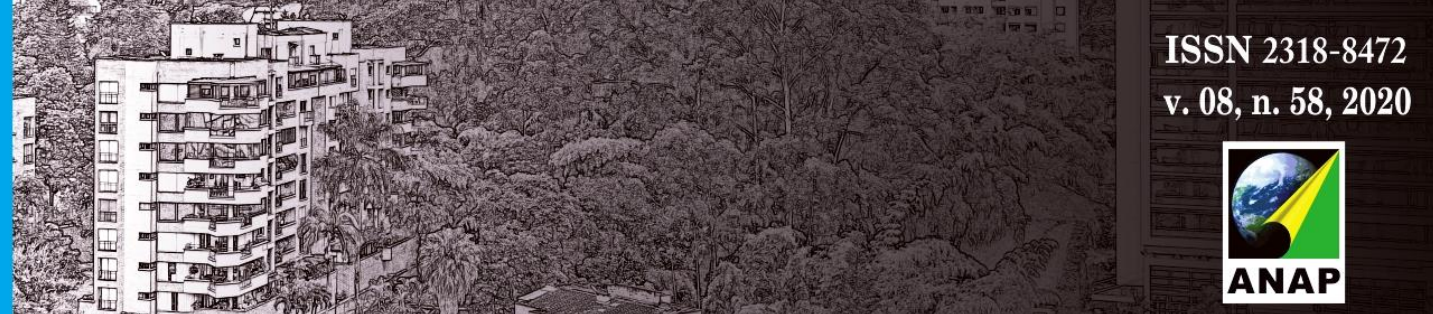

\section{Revista Nacional de}

Gerenciamento de Cidades

A ausência do acesso à cidade e à moradia adequada por essa população parece reduzir as moradias produzidas - nessa perspectiva, ao menos no caso estudado - somente à função de abrigo. Por sua vez, a função de abrigo também é enfraquecida, quando são observados os problemas construtivos encontrados nos Conjuntos Habitacionais Jaguariúna I e II. Aparentemente - de acordo com os relatos dos síndicos e dos levantamentos de dados, ao tentar contato com a construtora responsável e com a Caixa Econômica Federal - não há perspectiva de que os órgãos apresentem qualquer solução para esses defeitos. As falhas encontradas nas moradias abordadas, de acordo com as visitas ao local, as tornam insalubres. Isso porque muitas das falhas possuem relação com infiltração e baixa vedação, o que representa riscos à saúde dos usuários. Por isso, como já indicado, considera-se que mesmo a função de abrigo não é totalmente atendida.

\section{PADRÃO CONDOMINIAL PARA BAIXA RENDA}

Como visto anteriormente, os enclaves fortificados têm se multiplicado pelo território das cidades do Eixo Campinas-Mogi, e a produção de HIS pelo PMCMV reproduz o padrão condominial para baixa renda, permitindo e incentivando que os conjuntos habitacionais sejam executados dessa maneira. Porém, a aplicação desse padrão para baixa renda ${ }^{6}$ apresenta outros problemas, além daqueles já citados para os enclaves de forma geral. No padrão condominial, os problemas de convivência gerados por uma unidade de vizinhança nova são agravados, pois existem interesses em comum aos moradores. Esses problemas dificultam a gestão interna dos condomínios pelos síndicos. Outros problemas surgem do custo com a taxa condominial, que impacta diretamente o gasto com a moradia, que fica incompatível com o perfil socioeconômico da população residente, e da falta de costume dela com o padrão condominial, já que este não é amplamente difundido na realidade local.

No tocante à gestão dos problemas construtivos e de infraestrutura internos, o padrão condominial parece contribuir para a ausência de suporte prestado pelos órgãos públicos, uma vez que as redes que abastecem o condomínio, nas áreas comuns, são de responsabilidade do próprio condomínio. Isso porque, de acordo com a legislação brasileira, as áreas comuns de um condomínio se tornam propriedade particular, sendo que cada proprietário tem uma fração ideal daquelas áreas. Portanto, o poder público local não tem responsabilidade sobre a manutenção e as melhorias necessárias nas redes.

A questão da propriedade privada, no tocante à moradia popular, também é outro entrave para a gestão desses condomínios, ao ser a única modalidade prevista pelo PMCMV. Ao conceder a propriedade dos imóveis aos beneficiários da política social, o poder público perde o poder de administrar as moradias. Dessa forma, não é possível que - ao longo dos anos - com o desenvolver da vida dos moradores, o governo possa remanejar as unidades habitacionais, atendendo à outra demanda habitacional. Além disso, a propriedade do imóvel pode oferecer alguns riscos aos proprietários, como ser desapropriado para pagamento de dívidas e pressões externas para venda ou abandono dos imóveis, por outros extratos sociais, como já ocorreu em alguns conjuntos produzidos pelo PMCMV.

\section{CONSIDERAÇÕES FINAIS}

A localização dos Conjuntos Habitacionais Jaguariúna I e II revela que apenas o fato de estarem inseridos em meio à malha urbana consolidada não garante a "boa localização" da moradia. Os

\footnotetext{
6 Confira publicações de 2015 do LabCidade. Disponível em: <http://www.labcidade.fau.usp.br/biblioteca/artigos-ecapitulos/>. Acesso em 10 mar 2017.
} 


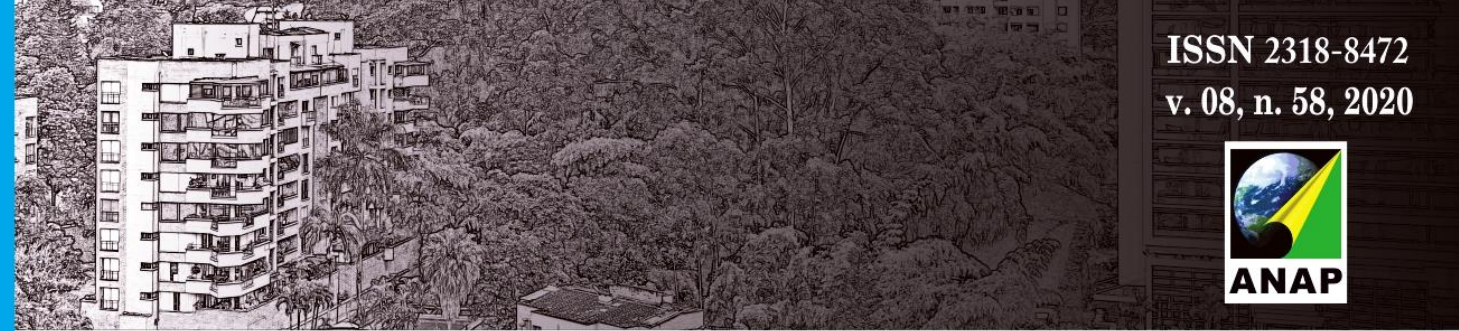

\section{Revista Nacional de}

Gerenciamento de Cidades

problemas de localização comprometem o direito à moradia adequada e à cidade, que são assuntos internacionais, mas já previstos pela legislação brasileira. Além disso, a maneira como os conjuntos são produzidos acentua os fenômenos causados pelo processo de urbanização dispersa, tanto na escala regional quanto na intra-urbana. Esses fenômenos, sentidos diretamente pela população, principalmente são traduzidos pelos longos trajetos diários; presença de enclaves fortificados; segregação socioespacial; e cidades fragmentadas.

Observa-se que a produção desses conjuntos obedece aos interesses privados e à busca pela reprodução do capital. A espoliação urbana, fruto da especulação, se utiliza desses investimentos para tirar a máxima valorização da terra urbana, usufruindo dos investimentos públicos na cidade que viabilizam a produção da moradia popular. A cidade como campo de reprodução do capital é essencial na busca por novos mercados para reprodução capitalista, sobretudo porque prevê a construção e reconstrução das cidades, gerando ciclos infindáveis de reprodução. Essa mesma condição faz com que a moradia popular na cidade se concentre nas periferias, onde o preço da terra é mais baixo, pela ausência de infraestrutura e distância das centralidades importantes. A ocupação das periferias acentua ainda mais a urbanização dispersa e os fenômenos urbanos decorrentes dela.

Os enclaves fortificados, presentes em territórios dispersos, embora não sejam interessantes para as cidades, tem organizado o novo modo de vida da população das regiões metropolitanas brasileiras, sobremaneira àquelas que se formaram após a década de 1970. Também na moradia popular se tem reproduzido esse padrão, principalmente pela falsa sensação de segurança oferecida pelos muros. Porém, o padrão condominial aplicado à baixa renda oferece mais dificuldades, como problemas de gestão e convivência; de aumento nos gastos com a moradia; e ausência de suporte dos órgãos públicos, uma vez que a área condominial se torna particular, e, portanto, de responsabilidade dos moradores.

\section{Referências Bibliográficas}

BRASIL. Decreto n. 7.499, de 16 de junho de 2011. Regulamenta dispositivos da Lei no 11.977, de 7 de julho de 2009, que dispõe sobre o Programa Minha Casa, Minha Vida, e dá outras providências. Diário Oficial da União, Brasília, 08 jul. 2009.

. Lei n. 12.424, de 16 de junho de 2011. Altera a Lei no 11.977, de 7 de julho de 2009, que dispõe sobre o Programa Minha Casa, Minha Vida - PMCMV e a regularização fundiária de assentamentos localizados em áreas urbanas. Diário Oficial da União, Brasília, 16 jun. 2011.

Lei n. 11.977, de 7 de julho de 2009. Dispõe sobre o Programa Minha Casa, Minha Vida - PMCMV e a regularização fundiária de assentamentos localizados em áreas urbanas. Diário Oficial da União, Brasília, 08 jul. 2009.

Ministério das Cidades. Dispõe sobre os parâmetros de priorização e o processo de seleção dos beneficiários do Programa Minha Casa, Minha Vida - PMCMV. Portaria n. 610, de 26 de dezembro de 2011. Diário Oficial da União, Brasília, 27 dez. 2011. Seção 1, p. 59-60.

Secretaria de Direitos Humanos da Presidência da República. Direito à Moradia Adequada. Brasília: Coordenação Geral de Educação em SDH/PR, Direitos Humanos, Secretaria Nacional de Promoção e Defesa dos Direitos Humanos, 2013. 76 p.

CALDEIRA, T. P. do R. Enclaves Fortificados: a nova segregação urbana. Novos Estudos, São Paulo, n 47, p. 155176, mar. 1997. 


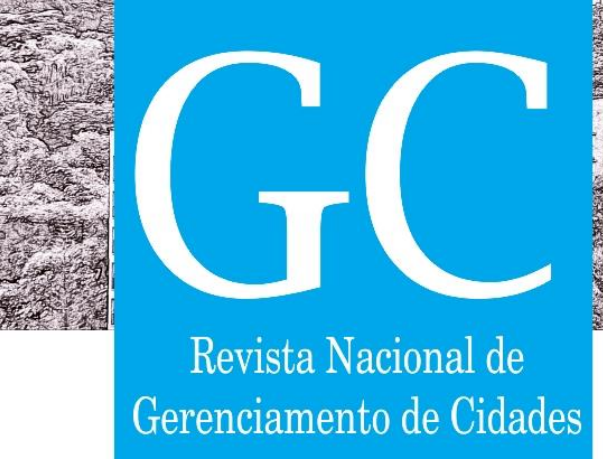

CASTELLS, M. The Information Age: Economy, Society and Culture. Hoboken: Blackwell Pub. Inc., 1998.

CHOAY, F. L'urbanisme: utopies et realites, une anthologie. Paris: du Seuil, 1965.

HARVEY, D. The Enigma of Capital: And the Crises of Capitalism. 2. ed. Oxford: Oxford University Press, 2010. Spaces of Capital: Towards a Critical Geography. UK: Routledge, 2001.

HOBSBAWM, E. J. Industry and Empire: From 1750 to the Present Day. 3. ed. Londres: Penguin Books, 1990.

MARICATO, E. Para entender a crise urbana. São Paulo: Expressão Popular, 2015. 112p.

. A terra é um nó, na sociedade brasileira... também nas cidades. Cultura Vozes. Petrópolis: Ed. Vozes., v. 93, n. 6, p. 7-22, 1999.

MONTEIRO, Márcia R. Dossiê Jaguariúna. Cadernos de Pesquisa do LAP, São Paulo: FAUUSP, n. 50, jan./jun. 2007.

ORGANIZAÇÃO DAS NAÇÕES UNIDAS (ONU). Pacto Internacional de Direitos Econômicos, Sociais e Culturais. Viena: 1966.

Declaração Universal de Direito Humanos. Viena: 1948.

ROLNIK, R. et al. O Programa Minha Casa Minha Vida nas Regiões Metropolitanas de São Paulo e Campinas: aspectos socioespaciais e segregação. Cadernos Metrópole (PUCSP), v. 17, p. 127-154, 2015.

REIS FILHO, N. G. Aglomerações urbanas e novas formas de tecido urbano: discussão sobre diretrizes para políticas públicas e políticas profissionais para intervenção. In: REIS FILHO, N.G.; TANAKA, M. S. (Coord.). Brasil: estudos sobre dispersão urbana. São Paulo: FAU-USP, 2007. P. 165-182. 2006.

Notas Sobre Urbanização Dispersas e Novas Formas de Tecido Urbano. São Paulo: Via das Artes,

SASSEN, S. The Mobility of Labor and Capital. Cambridge: Cambridge University Press, 1988.

SAULE JR., N. O Direito à Cidade e a Revisão da Lei de Parcelamento do Solo Urbano. In: (Org.). A Perspectiva do Direito à Cidade e da Reforma Urbana na Revisão da Lei do Parcelamento do Solo. São Paulo: Instituto Pólis, 2008. p. 7-29.

TAYLOR, George Rogers. The Transportation Revolution, 1815-1860. Reprint, New York, Routledge, 2015. 